\title{
Desain Awal Berbiaya Murah Spektrofotometri Berbasis Mikrokontroler untuk Uji Angka DOBI Crude Palm Oil (CPO)
}

\author{
Novelita W. Mondamina ${ }^{1 *}$, Hanifadinna ${ }^{1}$ \\ ${ }^{1}$ Institut Teknologi Sains Bandung, Teknologi Pengolahan Sawit, Cikarang Pusat, Bekasi, Jawa Barat 17530 \\ ${ }^{1}$ Corresponding author: novelita@itsb.ac.id
}

\begin{abstract}
Abstrak. Dalam proses pengolahan Tandan Buah Segar (TBS) menjadi minyak sawit mentah (Crude Palm Oil, CPO), standar dan mutu CPO harus diperhatikan. Salah satu cara mengendalikan mutu CPO adalah dengan melakukan analisis mutu dari beberapa sifat khas $\mathrm{CPO}$. Salah satu diantaranya adalah warna $\mathrm{CPO}$ kuning oranye yang berasal dari kandungan senyawa karoten. Uji analisis yang memanfaatkan senyawa karoten adalah uji angka Deterioration of Bleachability Index (DOBI) dengan menggunakan spektrofotometri UVVis. Program studi Teknologi Pengolahan Sawit (TPS) saat ini belum memiliki alat tersebut untuk pengukuran mutu CPO di laboratorium. Dalam penelitian ini akan dicoba untuk membuat spektrofotometri berbasis mikrokontroler yang juga memiliki keuntungan dari segi ekonomi serta aplikasi keilmuan instrumentasi dan kimia. Dari segi ekonomi, pembuatan spektrofotometri memiliki harga yang lebih murah dengan spektrofotometri konvensional. Selain itu dari segi keilmuan instrumentasi dan kimia, spektrofotometri ini merupakan salah satu aplikasi gabungan kedua keilmuan tersebut sehingga diharapkan dapat memperluas variasi penggunaan teknologi pengukuran. Serta juga memberikan pengetahuan kepada mahasiswa terkait gabungan beberapa keilmuan yang dapat dimanfaatkan untuk menjaga standar mutu CPO.
\end{abstract}

Kata kunci: Spektrofotometri, DOBI, sawit, karoten, pendidikan

\section{Pendahuluan}

\subsection{Latar belakang}

Parameter DOBI merupakan hal yang sangat krusial untuk diketahui dalam penentuan kualitas minyak sawit mentah (crude palm oil, CPO). Penentuan DOBI umumnya dilakukan menggunakan spektrofotometer pada laboratorium PKS (pabrik kelapa sawit). Program studi Teknologi Pengolahan Sawit (TPS) sudah selayaknya memiliki alat tersebut, namun hal ini terkendala oleh tingginya biaya pengadaan peralatan dibandingkan dengan fungsinya yang hanya menghasilkan parameter DOBI. Berdasarkan penelitian mengenai cara kerja dan sistematika jalannya cahaya dan penentuan panjang gelombang, untuk mendapatkan panjang gelombang tertentu untuk mendapatkan nilai DOBI ternyata bukanlah hal yang sulit. Hal ini bisa diupayakan dengan membuat perangkat instrumentasi yang dapat dibuat pada skala laboratorium.

\subsection{Tujuan penelitian}

Adapun tujuan penelitian ini adalah:

1. Membuat spektrofotometer berbasis mikrokontroler.

2. Menentukan nilai serapan panjang gelombang karoten dan volatile fatty acids (VFA) minyak sawit mentah.

3. Menentukan nilai perbandingan nilai serapan kedua senyawa karoten dan volatile fatty acids (VFA) minyak sawit (angka DOBI). 


\subsection{Batasan masalah}

Penelitian ini mencakup pembuatan spektrofotometer, pengukuran serapan panjang gelombang untuk karoten dan volatile fatty acids (VFA) minyak sawit dan perbandingan absorbansinya untuk menentukan nilai DOBI CPO. Serta perbandingan aplikasi spektrofotometer berbasis mikrokontroler dengan spektrofotometer konvensional untuk mengetahui relevansi penggunaan alat yang diteliti.

\subsection{Manfaat penelitian}

Pemanfaatan mikrokontroler pada pembuatan spektrofotometer dapat digunakan sebagai media pembelajaran mahasiswa untuk mengukur angka DOBI minyak sawit.

\section{Metode}

\subsection{Tahapan penelitian}

Secara umum tahapan penelitian mencakup aktivitas yang berada pada diagram alir berikut:

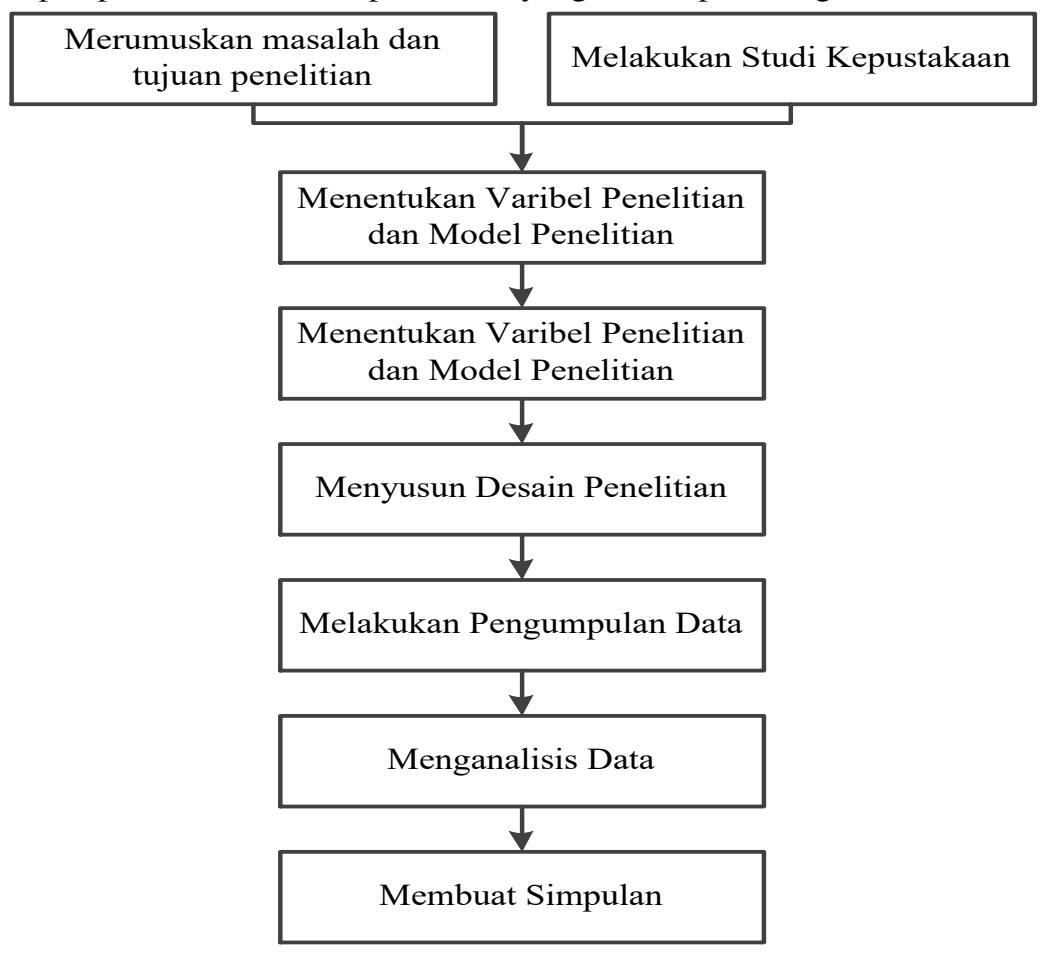

Gambar 21. Tahapan penelitian

\subsection{Lokasi penelitian}

Penelitian dilakukan di laboratorium fisika dasar dan kimia dasar Institut Teknologi Sains Bandung.

\subsection{Pengumpulan dan analisis data}

Teknik pengumpulan data yang digunakan dalam perancangan ini adalah melalui eksperimen. Eksperimen digunakan untuk mendapatkan data melalui perancangan sistem secara langsung di tempat lab yang meliputi perancangan alat dan pengumpulan data.

\subsection{Rancangan Rangkaian Sistem Pengukuran}

Secara umum rancangan sistem adalah untuk melewatkan berkas cahaya ke prisma atau kisi difraksi. Cahaya yang melewati prisma akan dibiaskan dan terurai menjadi spektrum cahaya dengan panjang gelombang tertentu. Panjang gelombang tertentu dipilih dengan mengirimkan berkas cahaya melalui suatu 
celah. Berkas cahaya kemudian melewati sampel dan mengenai detektor. Untuk mudahnya, proses pengambilan informasi dilakukan seperti digambarkan oleh diagram alir berikut:

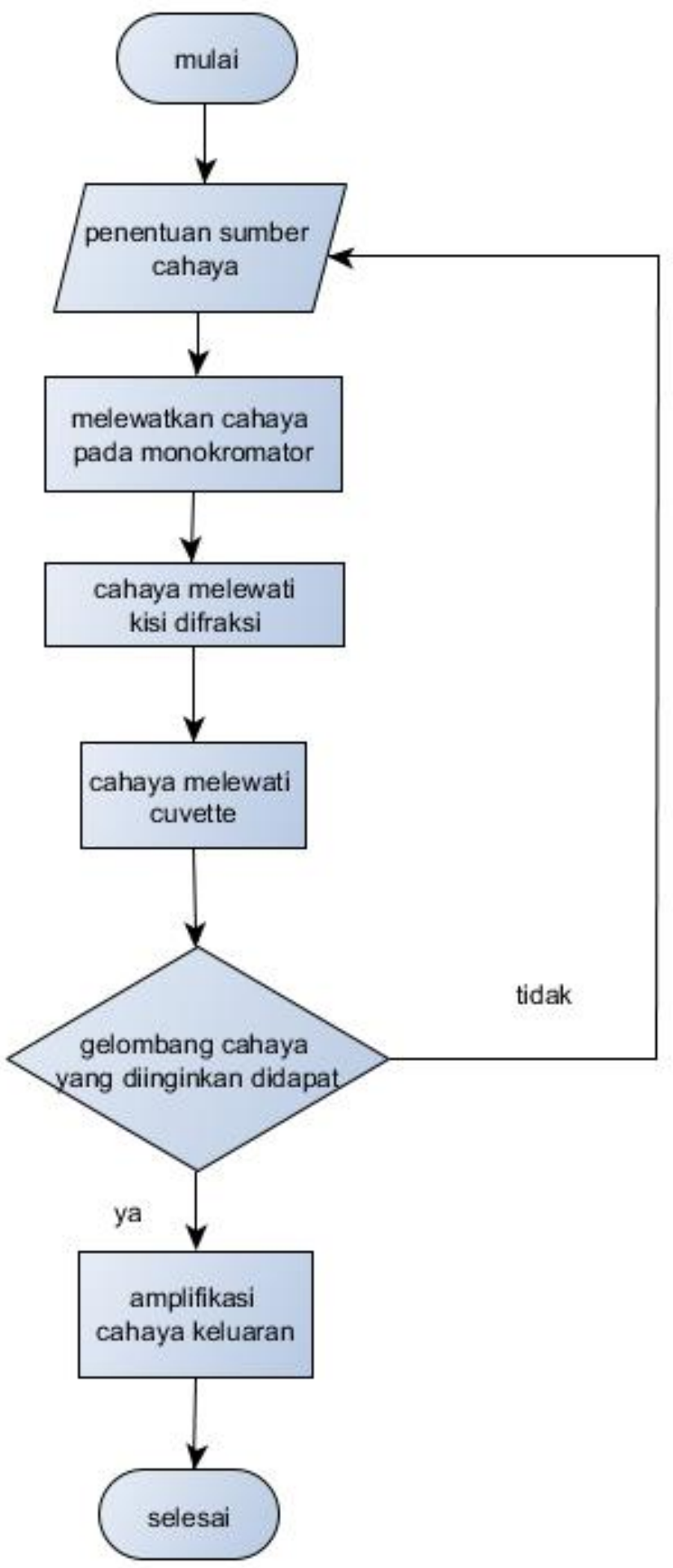

Gambar 22. Diagram alir proses pengambilan informasi

Mekanisme cahaya yang melewati kisi hingga didapat sinar tertentu adalah sebagai berikut: 


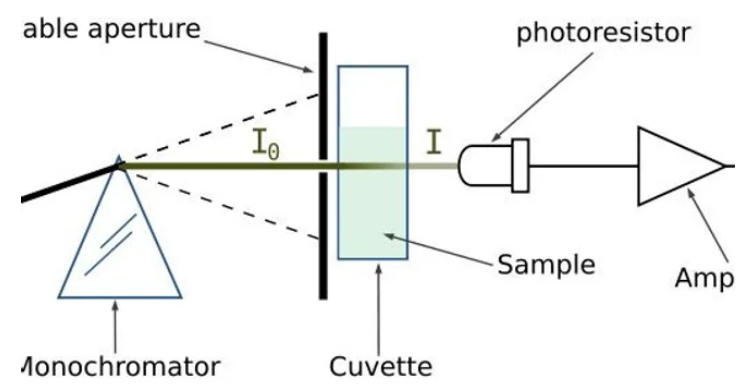

Gambar 23. Meknanisme cahaya Sumber : [1]

\subsection{Perancangan Sumber Cahaya}

Sumber cahaya dapat dihasilkan dari LED putih ataupun bola lampu. Untuk memenuhi kebutuhan dapat dipasang keduanya. Agar lampu memiliki posisi yang stabil, dibutuhkan fitting atau dudukan yang dapat dibuat dari $3 \mathrm{~d}$ printing maupun yang sudah tersedia di pasaran.

\subsection{Difraksi Cahaya}

Untuk dapat memilih cahaya dengan panjang gelombang tertentu, harus dilakukan pembelokan cahaya sehingga cahaya terurai menjadi spektrum-spektrum dengan ragam panjang gelombang. Pembelokan cahaya ini dapat dilakukan dengan membuat kisi difraksi yang telah tersedia di pasaran maupun membuatnya sendiri.

\subsection{Pemilihan Panjang Gelombang}

Pemilihan panjang gelombang dapat dilakukan dengan menggunakan lembaran logam yang diberi celah sempit. Untuk memilih bagian mana dari spektrum yang melewati celah, dapat divariasikan saat cahaya mulai menyentuh kisi. Untuk bisa mengatur variasi cahaya, dapat digunakan motor stepper agar kemunculan cahaya dapat diatur dengan cara diputar secara bertahap.

\subsection{Pengaturan Motor Stepper dengan Mikrokontroller}

Pada penelitian ini, mikrokontroller arduino digunakan untuk mengatur gerakan motor stepper. Rangkaian motor stepper bipolar dapat dilihat seperti pada gambar di bawah ini:

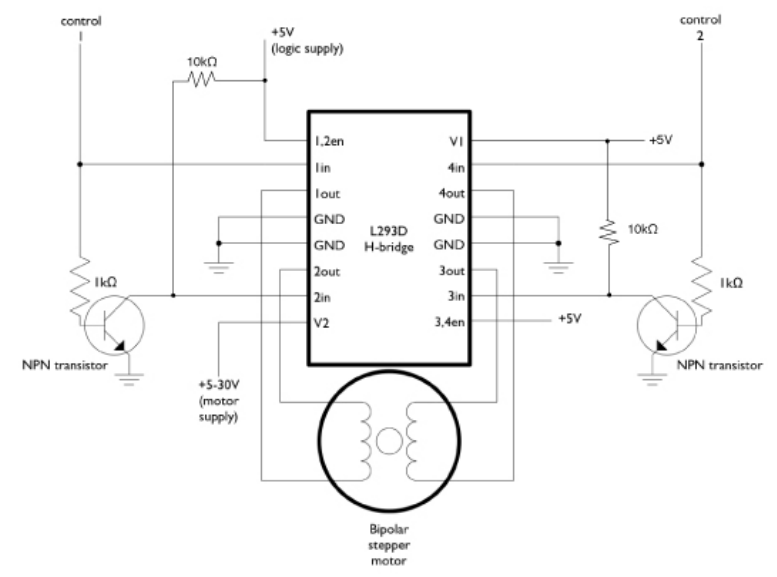

Gambar 24. Rangkaian stepper bipolar

Sumber : [2] 
Setelah motor stepper dirangkai seerti gambar diatas kita dapat memambahkan tombol dengan menghubungkan satu kaki resistor 2k2 (resistor pull-down) ke ground, dan kaki yang lain ke salah satu kaki push button untuk dihubungkan ke input digital pada Arduino. Kemudian, 1 kaki tombol yang lain ke $+5 \mathrm{~V}$ dari Arduino. Dengan rangkaian ini motor akan berputar 1 langkah saat tombol ditekan.

\subsection{Deteksi Cahaya}

Untuk mendeteksi cahaya cahaya yang melewati sampel, digunakanILight Dependent Resistor (LDR).

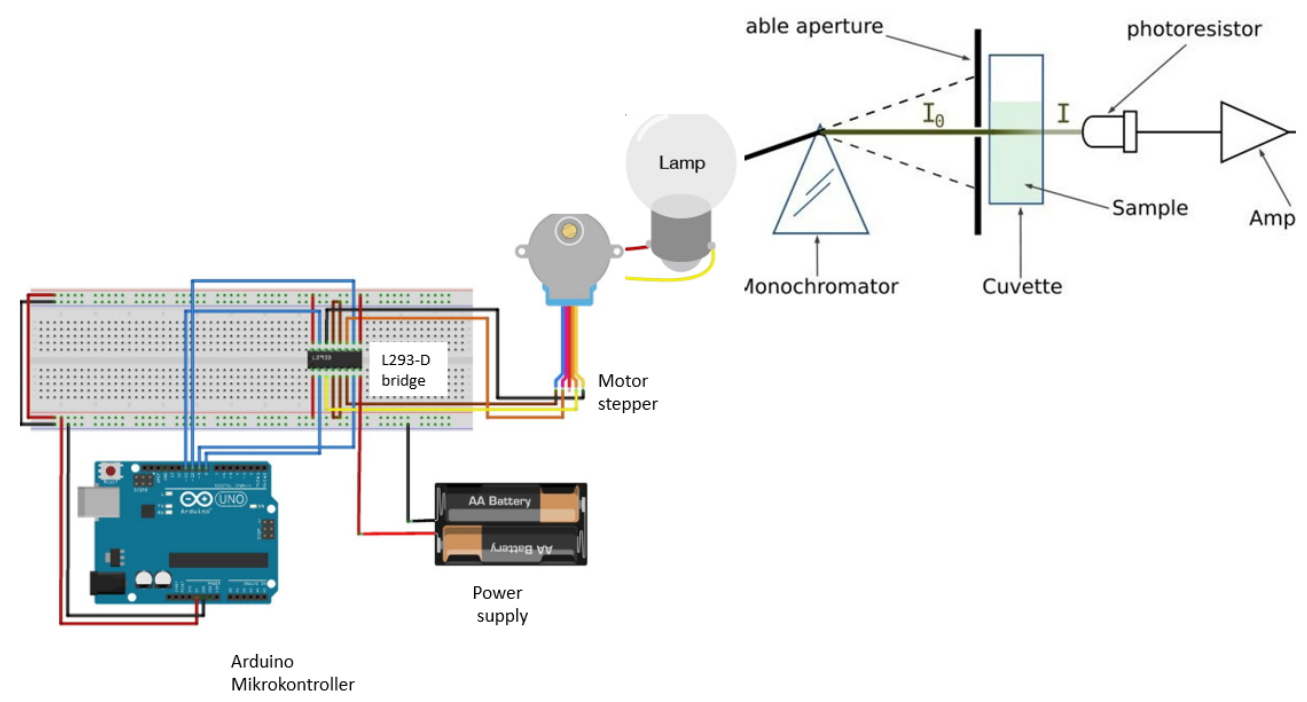

Gambar 25. Rangkaian Spektrofotometri Keseluruhan

Arduino berfungsi untuk menggerakkan motor stepper. Pergerakan motor stepper digunakan untuk mengarahkan lampu agar didapat panjang gelombang cahaya yang digunakan. Cahaya akan dibiaskan melalui monokromator dan dipilah melalui slit [3], [4]. Intensitas cahaya terukur sebelum kuvet (I0) dan setelah melewati kuvet (I) digunakan untuk menentukan nilai absorbansi sebagai berikut [5].

$$
A=\log \frac{I_{0}}{I}
$$

Nilai DOBI didapatkan dari perbandingan absorbansi cahaya pada panjang gelombang 446 nm (senyawa beta karoten) dan absorbansi cahaya pada panjang gelombang $269 \mathrm{~nm}$ (senyawa VFA) dari sampel CPO yang dirumuskan sebagai berikut:

$$
D O B I=\frac{A_{\lambda 446}}{A_{\lambda 269}}
$$

\section{Hasil dan pembahasan}

\section{A. Pembuatan Body Spektrofotomoter}

Kerangka spektrofotometer memanfaatkan wadah berwarna gelap untuk penyerapan panjang gelombang yang sempurna seperti diperlihatkan pada gambar. Beberapa hal yang dipersiapkan untuk membuat perangkat spektrofotometer skala lab ini antara lain: 
Wadah kotak dengan ukuran panjang $39.5 \mathrm{~cm}$, lebar $26.5 \mathrm{~cm}$ dan tinggi $15 \mathrm{~cm}$.

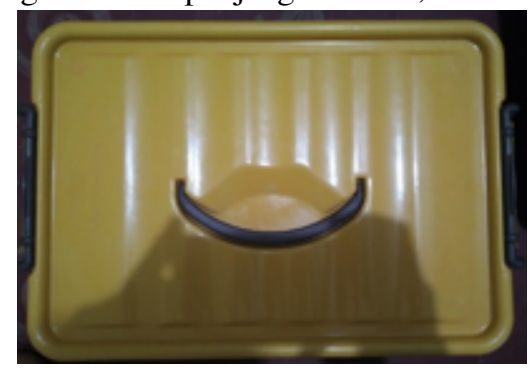

(a)

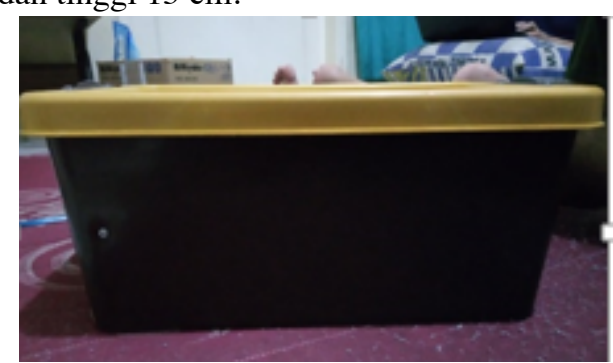

(b)

Gambar 26. Wadah spektrofotometer (a) tampak atas (b) tampak bawah

Membuat lubang pada kotak untuk LCD $(7.2 \times 2.5 \mathrm{~cm})$, potensio (diameter $0.6 \mathrm{~cm})$ dan port USB $(1.4 \mathrm{x}$ $1.4 \mathrm{~cm})$.

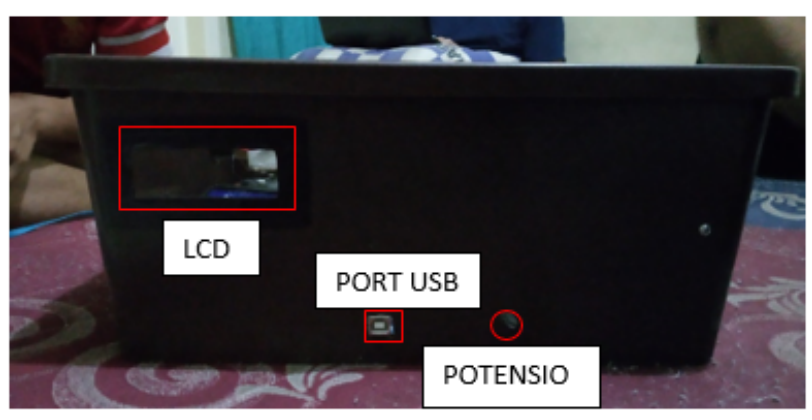

Gambar 27. Wadah sspektrofotometer yang telah diberi lubang

\section{B. Pembuatan Slit, Dudukan Motor Stepper, dan Dudukan Slit}

Slit dibuat dengan melubangi tripleks berukuran $25.5 \mathrm{~cm}$ x $14 \mathrm{~cm}$, seperti pada Gambar 28 .

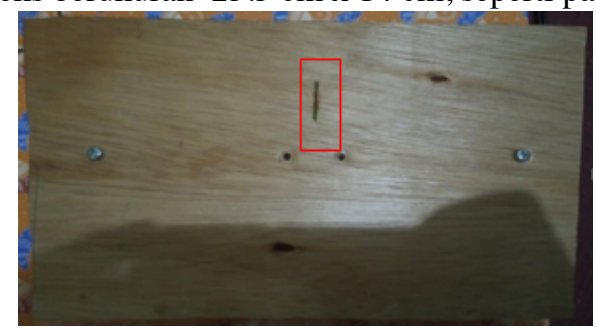

Gambar 28. Pembuatan slit pada tripleks

Membuat dudukan motor dengan ukuran panjang $22 \mathrm{~cm}$, lebar $7 \mathrm{~cm}$, dan tinggi $6 \mathrm{~cm}$.

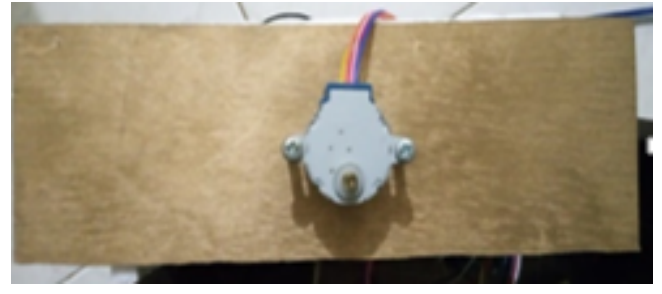

(a)

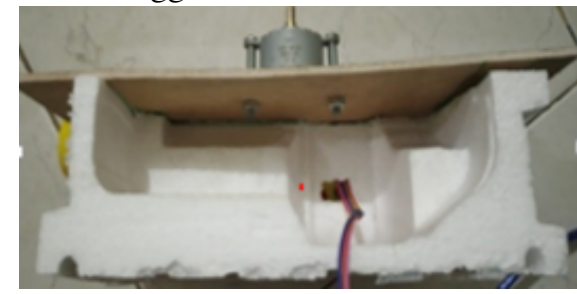

(b)

Gambar 29. Dudukan motor stepper

Membuat dudukan kuvet menggunakan triplek dengan ukuran panjang $2 \mathrm{~cm}$, lebar $1.7 \mathrm{~cm}$ dan tinggi 3.5 $\mathrm{cm}$. Dibuat lubang di belakang untuk memasukkan kaki LDR. Siku disatukan dengan cara dilem agar dudukan kuvet dapat ditempel pada slit dengan menggunakan baut. 


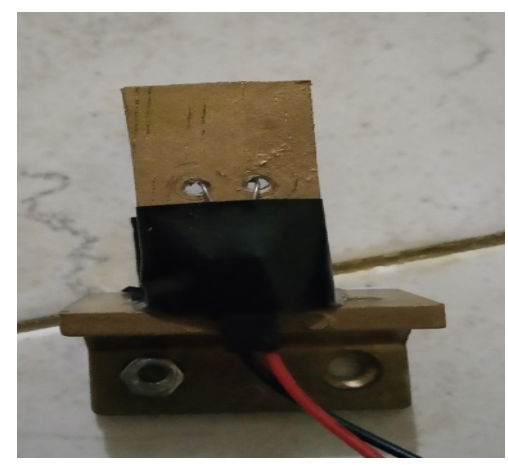

Gambar 30. Dudukan kuvet

\section{Rangkaian Keseluruhan}

Rangkaian elektronika pada Gambar 25 disusun dan diberi penambahan berupa LCD untuk pembacaan intensitas cahaya untuk setiap panjang gelombang yang mengenai sampel.

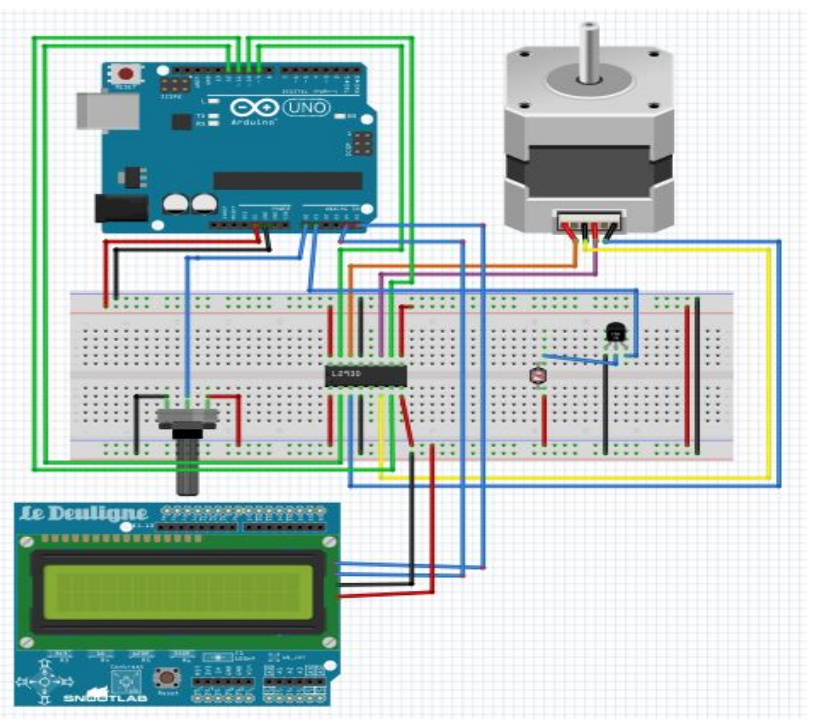

Gambar 31. Rangkaian elektronika Sepektrofotometer dengan LCD

Seluruh rangkaian elektronika dan dudukan perangkat disusun dalam kotak seperti terlihat pada Gambar 32. Kotak berwarna hitam digunakan untuk mencegah cahaya terfokus pada LDR, sehingga LDR hanya mendeteksi cahaya yang keluar dari kuvet.

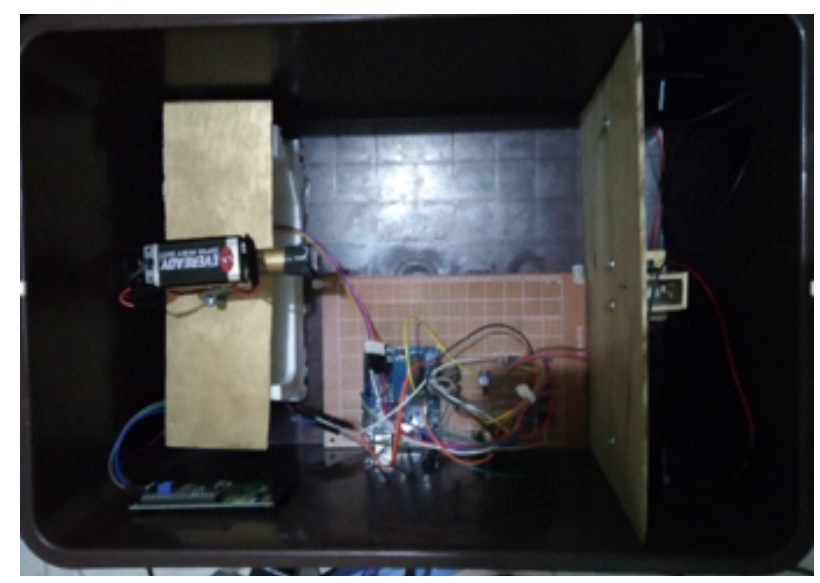

Gambar 32. Rangkaian keseleuruhan alat dalam kotak hitam 


\section{Pengukuran Larutan Blanko (Blank Measurement)}

Sebelum melakukan pengukuran sebenarnya (real measurement) yaitu pengukuran terhadap crude palm oil (CPO), dilakukan kalibrasi dengan menggunakan larutan blanko (isopropil alcohol). Pengukuran larutan blanko dilakukan untuk menjadi standar pada pengukuran panjang gelombang yang sama terhadap suatu sample. Selain itu LDR akan bereaksi berbeda terhadap setiap panjang gelombang.

Pengukuran terhadap sampel CPO dilakukan untuk mencari nilai absorbansi karoten $(\lambda=446 \mathrm{~nm})$ dan VFA $(\lambda=269 \mathrm{~nm})$. Nilai absorbansi didapat dengan melakukan pengukuran intensitas cahaya pada panjang gelombang $446 \mathrm{~nm}$ dan $269 \mathrm{~nm}$ kemudian membandingkannya. Nilai tersebut didapat saat motor stepper berputar pada sudut tertentu, kemudian ditangkap oleh $\mathrm{CD}$ dan dipantulkan menuju slit. Slit akan menyeleksi sinar dan sinar akan diteruskan menuju kuvet. LDR akan menangkap perubahan panjang gelombang dan hasil pembacaannya dapat dilihat pada LCD yang telah dipasang pada body kotak.

\section{Kesimpulan dan saran}

Penelitian ini menitikberatkan pada pembuatan spektrofotometer dengan harga terjangkau dengan mekanisme kerja alat yang dapat dipahami secara langsung oleh mahasiswa. Hal yang perlu diperhatikan adalah penggunaan cahaya UV untuk perangkat sehingga nilai panjang gelombang untuk beta karoten dan VFA dapat diperoleh. Penelitian ini merupakan langkah awal untuk merancang spektrofotometer yang lebih rigid dan mampu menggantikan penggunaan Spektrofotometer konvensional.

\section{Ucapan terima kasih}

Ucapan terima kasih diberikan kepada ITSB sebagai pihak pemberi dana serta partisipasi mahasiswa Teknologi Pengolahan Sawit ITSB 2017 yang telah membantu uji coba pengukuran sampel CPO dengan alat yang telah didesain.

\section{Daftar pustaka}

[1] Anonymous, 'Spectrophotometer: Working Principle, Use and Applications', All Medical Tests, 12-Feb-2017.

[2] Arduino, 'Arduino - Stepper Bipolar Circuit', 2019. [Online]. Available: https://www.arduino.cc/en/Reference/StepperBipolarCircuit. [Accessed: 27-Mar-2019].

[3] C. Kalkbrenner, A. Van, T. Smith, and D. Charles, 'Low-Cost Spectrophotometer'. 2013.

[4] G. Ó. Sölvason and J. T. Foley, 'Low-cost Spectrometer for Icelandic Chemistry Education', Procedia CIRP, vol. 34, pp. 156-161, 2015.

[5] M. G. Mellon, 'Analytical experiments in spectrophotometry', Journal of Chemical Education, vol. 19, no. 9, p. 415, Sep. 1942. 